Marek KROK

Janusz PORZYCKI

Roman WDOWIK

Politechnika Rzeszowska

\title{
PARAMETRYCZNE PROGRAMOWANIE SZLIFOWANIA WYROBÓW CERAMICZNYCH O ZLOŻONEJ GEOMETRII
}

\begin{abstract}
Wytwarzanie wyrobów z ceramiki technicznej o złożonej geometrii wymaga zastosowania maszyn CNC o określonych możliwościach technologicznych, specjalnych narzędzi ściernych oraz właściwie opracowanych programów sterujących. W artykule pokazano parametryczne programowanie obróbki przedmiotów wykonanych z ceramiki technicznej na szlifierce do wałków z osią C sterowaną numerycznie. Przedstawiono również analizę czasu obróbki typoszeregu części o sparametryzowanej geometrii.
\end{abstract}

Słowa kluczowe: programowanie parametryczne, szlifowanie, szlifierka CNC, wyroby ceramiczne

\section{Wprowadzenie}

Zapotrzebowanie na wyroby ceramiczne o złożonej geometrii prowadzi do potrzeby doskonalenia maszyn technologicznych sterowanych numerycznie oraz realizowanych na nich procesów obróbki. Ponieważ obróbka ceramiki technicznej po końcowym spieczeniu (rys. 1.) jest możliwa przez zastosowanie procesów obróbki ściernej, doskonalenie tych procesów staje się istotnym zagadnieniem współczesnej technologii obróbki ceramiki [1-3].

Ze względu na duży popyt ze strony krajowych i zagranicznych przedsiębiorstw na ceramiczne części maszyn o złożonych kształtach (rys. 2.), przy braku wytycznych prowadzenia obróbki, oraz potrzebę podnoszenia efektywności (w tym wydajności) procesów, przed przedsiębiorstwami związanymi z produkcją ceramicznych części maszyn są stawiane wyzwania technologiczne polegające na opracowaniu i wdrażaniu właściwych technologii, które umożliwią reagowanie na potrzeby rynku oraz spowodują ich dalszy rozwój. 


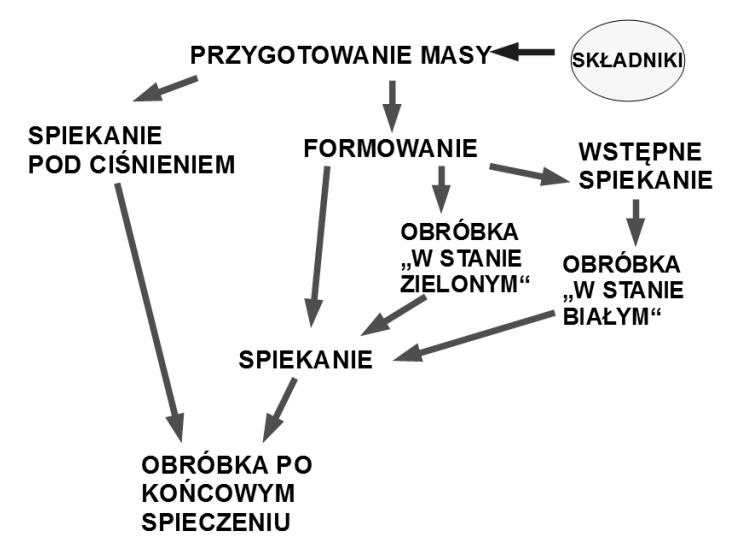

Rys. 1. Przebieg procesu technologicznego dla wyrobów ceramicznych

Fig. 1. The course of technological process of ceramic products

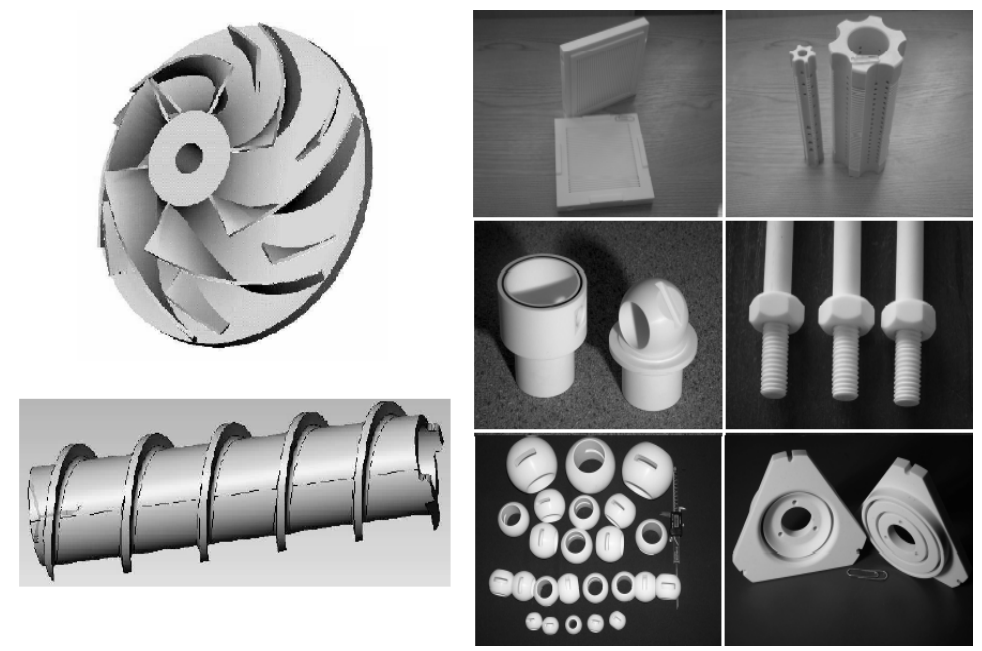

Rys. 2. Przykłady ceramicznych wyrobów o złożonej geometrii, opracowano na podstawie [4]

Fig. 2. Examples of ceramic products with complex geometry, prepared on the basis of [4]

\section{Wytwarzanie wyrobów z ceramiki na szlifierce CNC do wałków}

Przykładem wyrobów ceramicznych, których produkcja seryjna lub wielkoseryjna może $\mathrm{w}$ niedalekiej przyszłości osiągać znaczące wyniki, są przedmioty z owalnym zarysem przekroju. Są one wykonywane na szlifierkach do wałków 
(rys. 3.), których kinematyka umożliwia sterowanie ruchem punktu charakterystycznego ściernicy względem układu współrzędnych przedmiotu w osiach prostoliniowych $\mathrm{X}$ i Z oraz osi obrotowej $\mathrm{C}$ (rys. 5.). Ważnym zagadnieniem w produkcji wyrobów ceramicznych jest konieczność efektywnej obróbki części podobnych, tzn. typoszeregu wyrobów o różnych wymiarach. Rysunek 3. przedstawia przykładowy przedmiot obrabiany z ceramiki technicznej, który może stanowić wybrany element z typoszeregu wymiarowego pokazanego na rys. 6 .
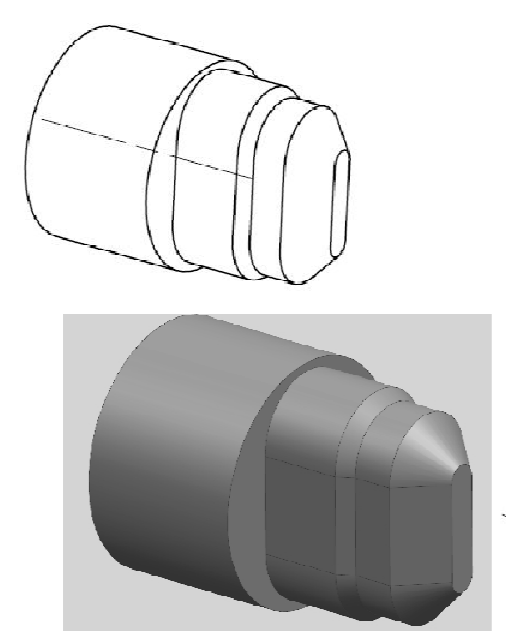
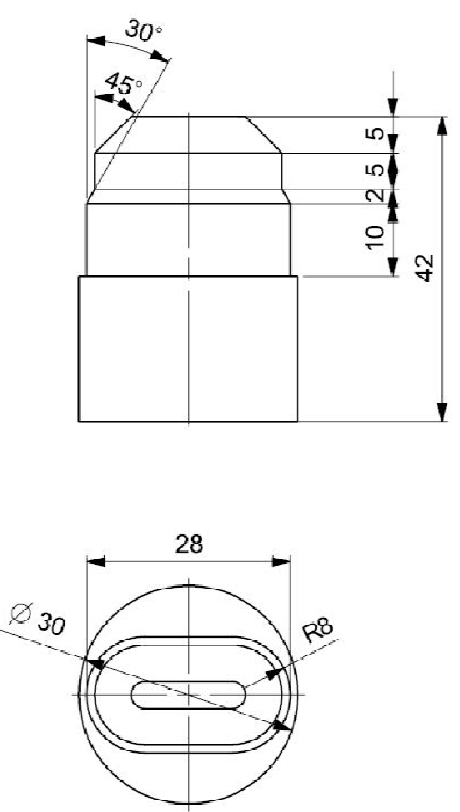

Rys. 3. Przykładowy przedmiot obrabiany z ceramiki technicznej

Fig. 3. Example of a workpiece made of technical ceramic

\section{Szlifierka CNC RUP 28 z układem Sinumerik 840Di}

W Katedrze Technik Wytwarzania i Automatyzacji Politechniki Rzeszowskiej została wdrożona (w 1992 r.) szlifierka typu RUP 28 z prototypowym polskim układem CNC NUMS 740. Wdrożenie szlifierki było wynikiem realizacji wielu prac w ramach CPBR 6.1 cel 70.4. Aby możliwe było wykorzystanie szlifierki RUP 28 do prac badawczych i produkcyjnych, konieczna była jej modernizacja (ze względu na przestarzały układ sterujący) i zastosowanie nowoczesnego układu CNC. Do sterowania obrabiarki wykorzystano układ CNC Sinumerik 840Di (rys. 4.), który umożliwia sterowanie osiami prostoliniowymi X i Z oraz osią obrotową C (rys. 5.). 


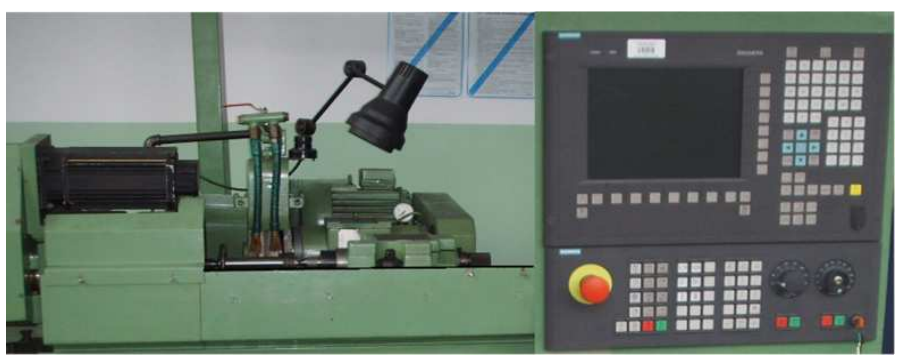

Rys. 4. Szlifierka RUP 28 z układem CNC Sinumerik 840Di

Fig. 4. RUP 28 grinding machine with CNC Sinumerik 840Di control

a)

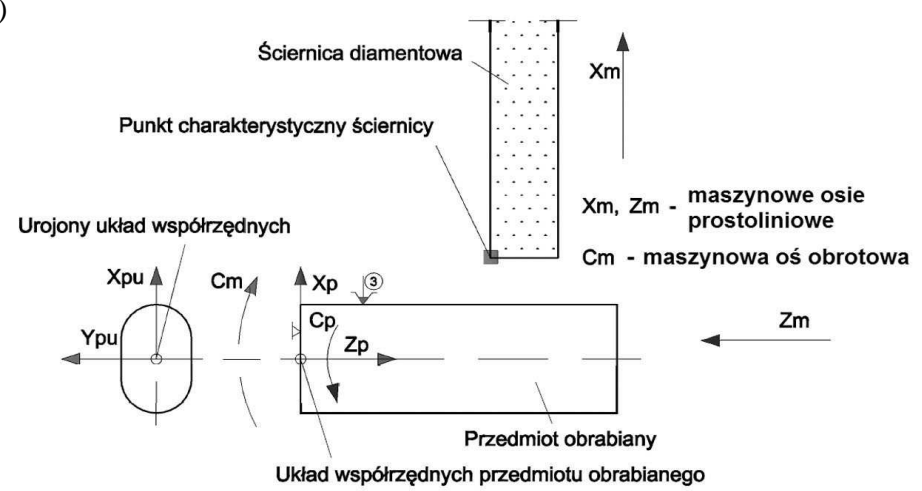

b)

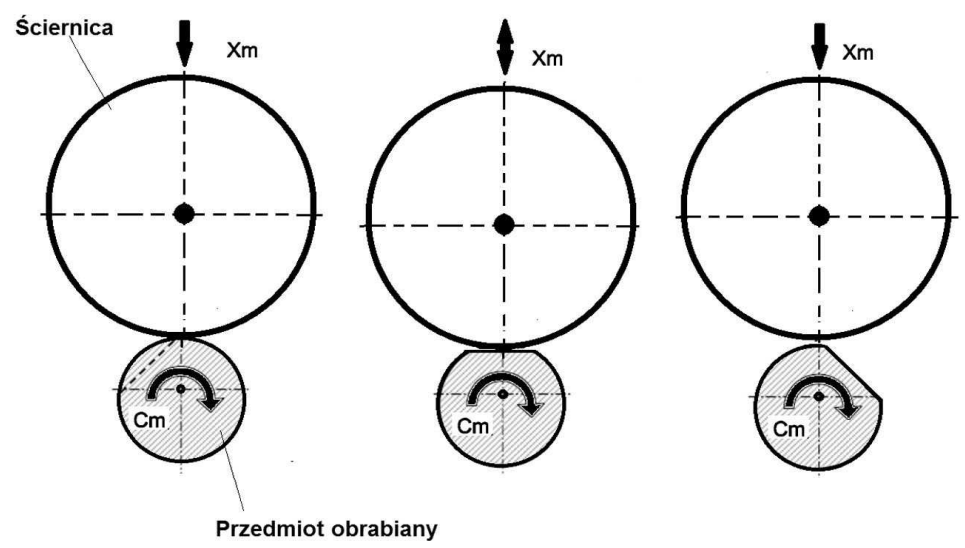

Rys. 5. Obróbka z osią maszynową Cm na szlifierce RUP 28 CNC: a) osie maszynowe i układy współrzędnych, b) zasada obróbki konturu podczas sprzężenia osi maszynowych $\mathrm{Xm}$ i Cm

Fig. 5. Machining with $\mathrm{Cm}$ machine axis on RUP $28 \mathrm{CNC}$ grinding machine: a) axes and coordinate systems, b) principle of contour machining (coupling of $\mathrm{Xm}$ and $\mathrm{Cm}$ axes) 


\section{Programowanie obróbki typoszeregu wyrobów o sparametryzowanej geometrii}

\subsection{Typoszereg wymiarowy wyrobów ceramicznych}

Przykładowy typoszereg wymiarowy wyrobów ceramicznych (odniesiony do przedmiotu z rys. 3.) przedstawia rys. 6. Dwanaście wyrobów (od M1 do M12) różni się promieniem zaokrąglenia części środkowej (od R13 do R2), co diametralnie zmienia kształt wyrobów i wpływa znacząco na przebieg procesu obróbki.
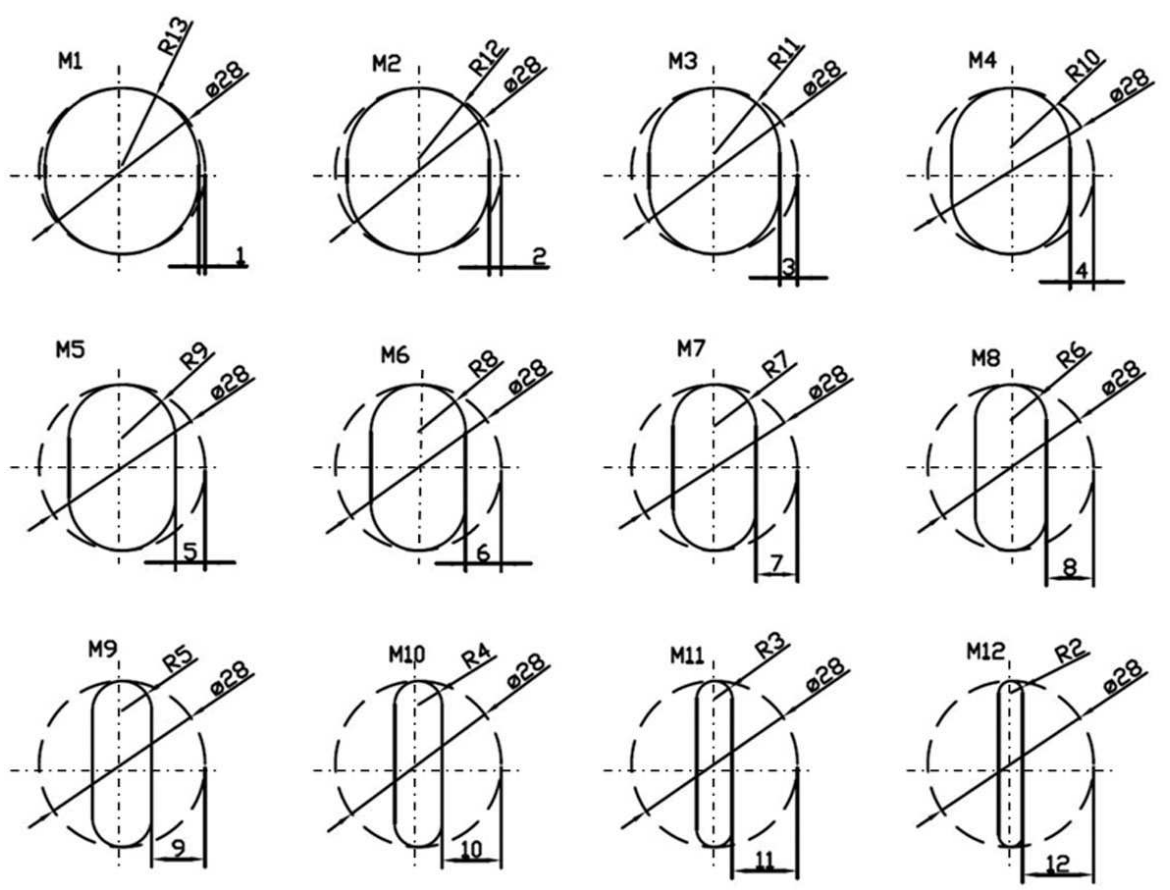

Rys. 6. Typoszereg wymiarowy wyrobów ceramicznych

Fig. 6. Type dimension of ceramic products

\subsection{Sparametryzowany program sterujący}

Programowanie toru ruchu ściernicy dla szlifierki RUP 28 CNC może odbywać się przez zastosowanie osi prostoliniowych w układzie prostokątnym lub biegunowym, natomiast programowanie ruchu $\mathrm{z}$ dodatkową osią $\mathrm{C}$ przez zadawanie współrzędnych końca ruchu osi $\mathrm{C}, \mathrm{X}, \mathrm{Z}$ lub przez zastosowanie funkcji TRANSMIT, co opisano w pozycjach [5, 6]. Na rysunku 7. wyjaśniono parametry przyjęte do opracowania programu obróbki typoszeregu części z rys. 5. 
W tabeli 1. przedstawiono opracowany program sterujący (główny i podprogram) przeznaczony do obróbki typoszeregu wyrobów określonych sparametryzowaną geometrią z rys. 7. dla szlifierki RUP 28 CNC z układem Sinumerik 840Di.

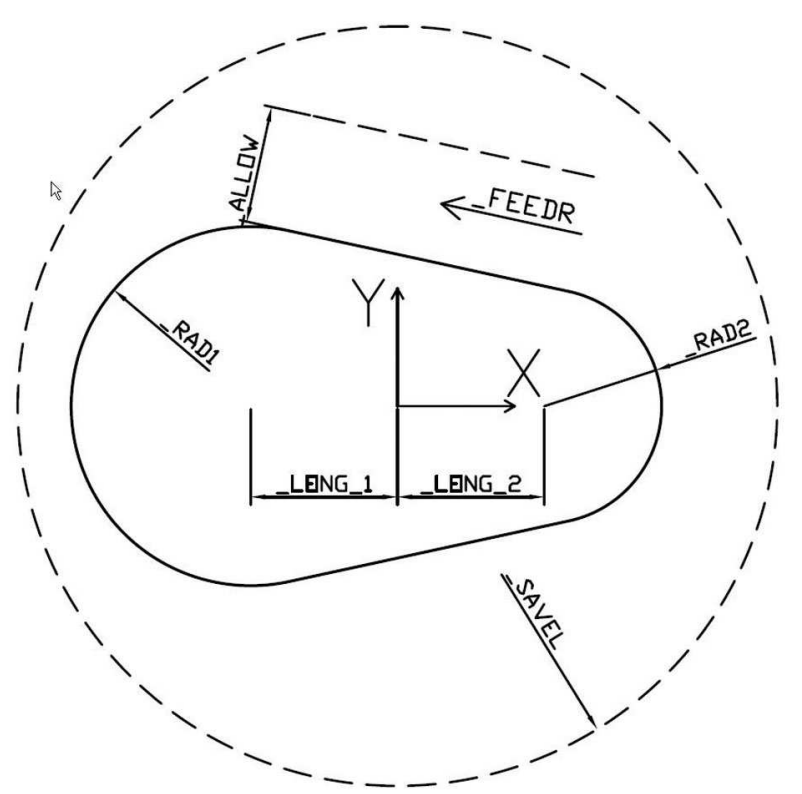

Rys. 7. Rysunek pomocniczy do opracowania programu obróbki

Fig. 7. Auxilary draft to work out of machining program

Tabela 1. Program główny \%_N_PROG_MPF oraz podprogram \%_N_PROG_SPF

Table 1. Main program \%_N_PROG_MPF and subprogram \%_N_PROG_SPF

\begin{tabular}{|l|}
\hline \%_N_PROG_MPF \\
EXTERN CYCLE_CAM(REAL,REAL,REAL,REAL,REAL,REAL,REAL,REAL,REAL,REAL) \\
G54 \\
WORKPIECE(,,"CYLINDER",0,0,-20,-10,30) \\
T="CUTTER" \\
;T="PLUNGE_CUTTER_3 A" \\
;T="ROUGHING_T80 A" \\
SETMS(3) \\
S4000 M3 \\
CYCLE_CAM(-1,13,1,13,1,0,0.01,2,4000,10) \\
SPOS[1]=90 \\
M30 \\
\hline \%_N_PROG_SPF \\
N10 PROC CYCLE_CAM(REAL_LEVEL, REAL_RAD1, REAL_LENG1, REAL_RAD2, REAL \\
_LENG2, REAL_ANG, REAL_AP, REAL_ALLOW, REAL_FEEDR, REAL_SAVEL) SAVE \\
; DEFINICJA CYKLU WRAZZZTYPEM ORAZ NAZWĄ PRZYJMOWANYCH PARAMETRÓW: \\
;_LEVEL_POZYCJA W OSI WZDEUŻNEJ \\
;_RAD1,_RAD2 - PROMIENIE ZAOKRAGLENIA KRZYWWI \\
;_LENG1,_LENG2 - POŁOŻENIA ŚRODKÓW OKRĘGÓW KRZYWKI \\
\hline
\end{tabular}




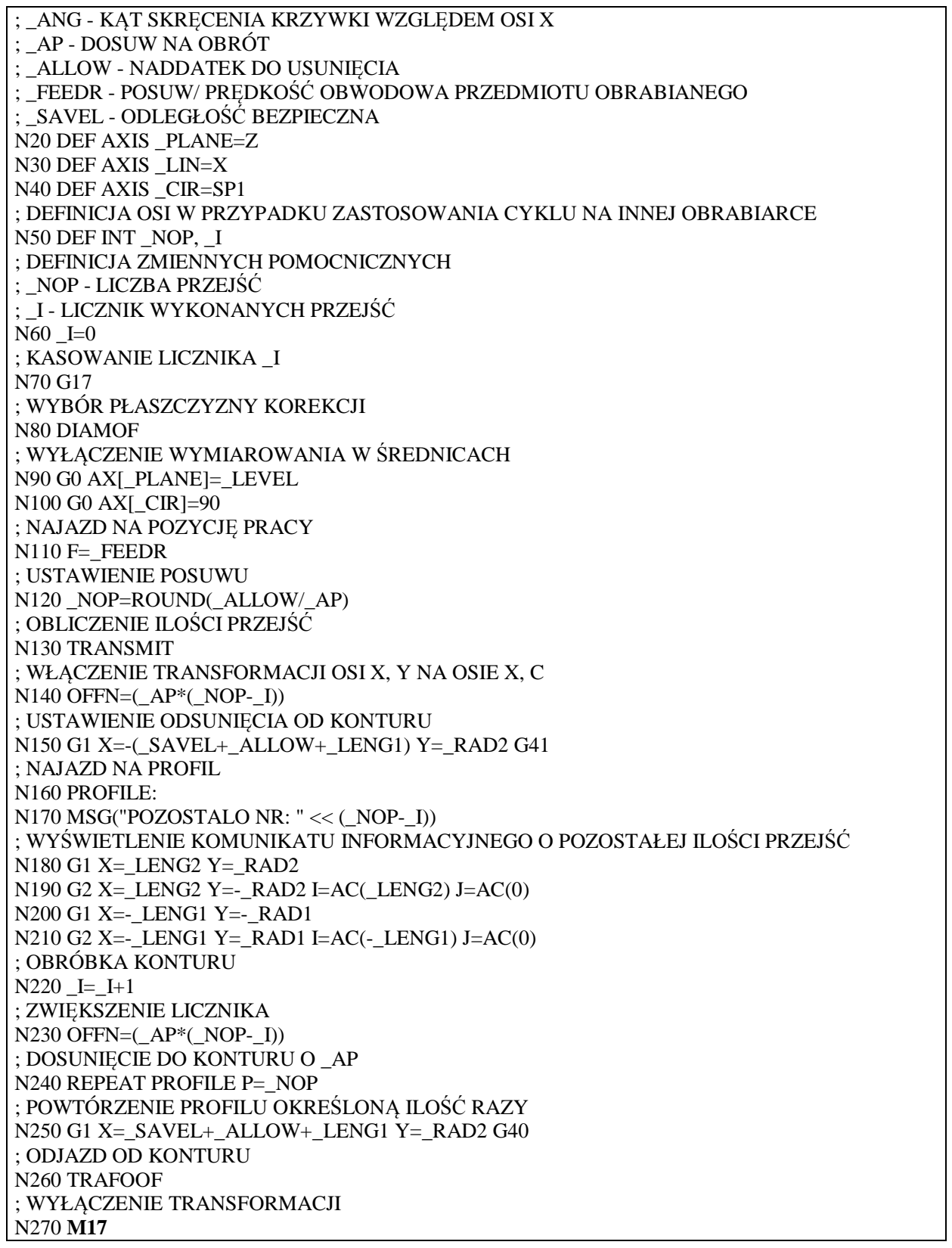

Aby sprawdzić program obróbki, należy dokonać jego symulacji. Na rysunku 8. przedstawiono ekran układu Sinumerik 840Di, na którym jest widoczny tor ruchu punktu charakterystycznego ściernicy podczas symulacji obróbki jednego 
z przedmiotów ich typoszeregu. Na podstawie symulacji można określić czas obróbki przedmiotu.

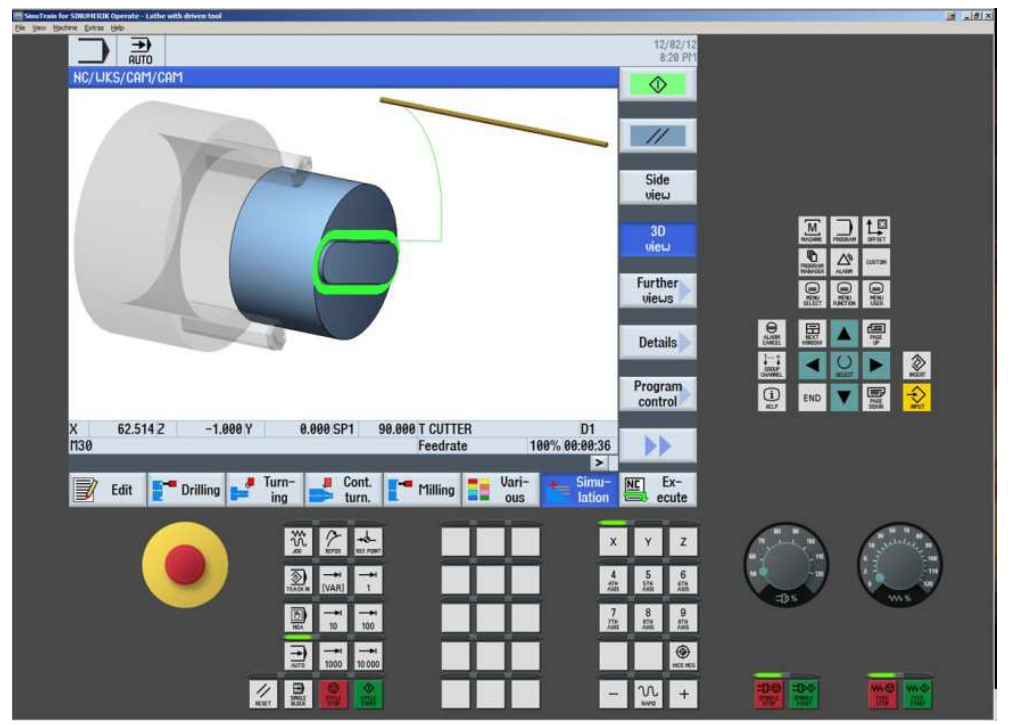

Rys. 8. Ekran symulatora układu Sinumerik 840Di

Fig. 8. Screen of Sinumerik 840Di simulator

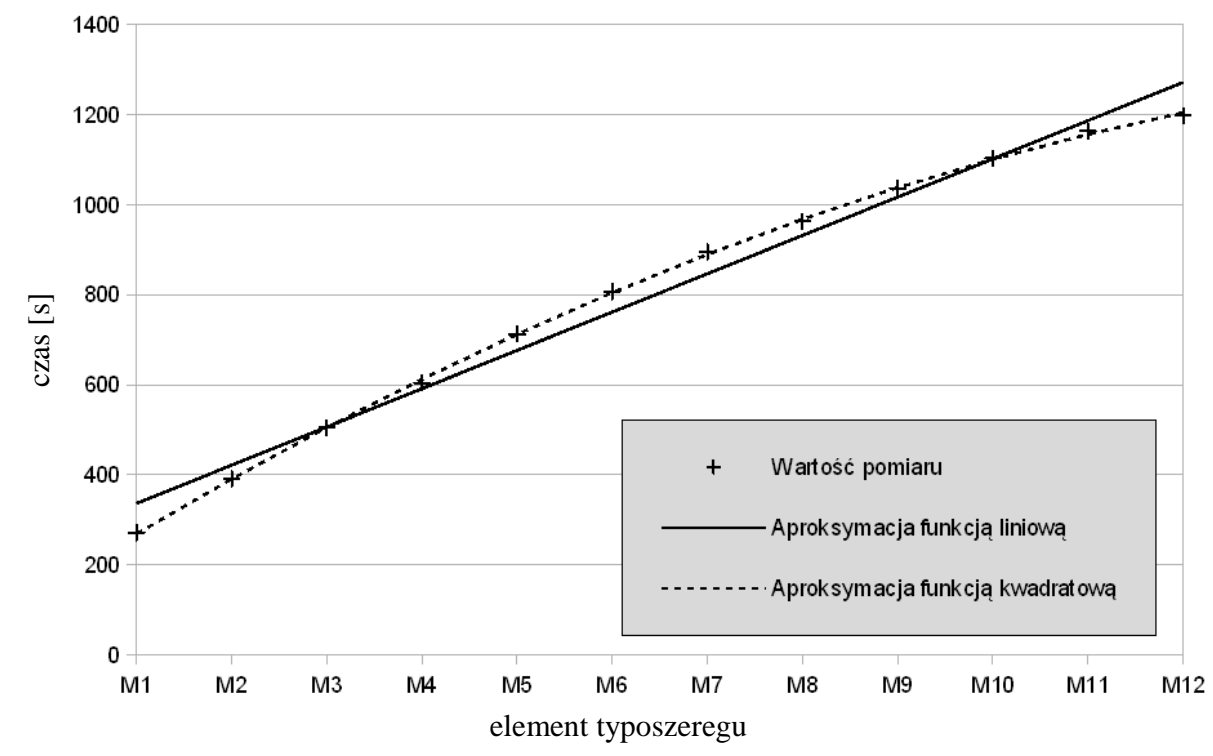

Rys. 9. Czas obróbki typoszeregu wyrobów

Fig. 9. Time of machining of type dimension products 


\subsection{Analiza czasu obróbki}

Ważnym czynnikiem podczas planowania produkcji danego wyrobu jest znajomość głównego czasu obróbki. Rysunek 9. przedstawia czas obróbki typoszeregu części (od M1 do M12) z rys. 6. dla tych samych parametrów technologicznych. Zmienny czas wynika z różnicy drogi, jaką przebędzie punkt charakterystyczny ściernicy względem przedmiotu obrabianego podczas obróbki poszczególnych przedmiotów za pomocą tego samego sparametryzowanego programu obróbkowego.

\section{Podsumowanie}

Ceramika techniczna ze względu na swoje właściwości użytkowe coraz częściej znajduje zastosowanie jako materiał konstrukcyjny. Obróbka wyrobów $\mathrm{z}$ ceramiki nie jest jednak łatwa, gdyż materiał ten należy do trudno obrabialnych. $\mathrm{Z}$ tego powodu szczególnie obróbka wykończeniowa jest realizowana za pomocą szlifowania $\mathrm{z}$ użyciem ściernic diamentowych. Wyroby ceramiczne o złożonej geometrii wymuszają także stosowanie do ich obróbki zaawansowanych wieloosiowych maszyn CNC, dla których konieczne jest właściwe opracowanie programu sterującego. Zastosowanie programowania parametrycznego upraszcza program sterujący, skraca jego długość, a przede wszystkim umożliwia obróbkę typoszeregu wyrobów za pomocą tego samego programu z różnymi wartościami parametrów. Ten sposób programowania upraszcza również wyznaczanie czasu obróbki każdego przedmiotu ze zbioru objętego typoszeregiem wyrobów, co ma znaczenie podczas planowania produkcji. Mimo doskonalenia różnych sposobów obróbki skrawaniem materiałów w stanie twardym, można twierdzić, że szlifowanie nadal zachowuje zdolność konkurowania z nimi dzięki stałemu postępowi zachodzącemu w budowie ściernic, szlifierek i w stosowanych procesach [7]. W odniesieniu do ceramiki technicznej po końcowym spieczeniu jest ona przykładem efektywnej techniki jej obróbki ubytkowej.

\section{Literatura}

[1] Manison P.: Technical ceramics - tough benefits, World Pumps, May 2009.

[2] Liang Y., Dutta S.P.: Application trend in advanced ceramic technologies, Technovation, 21 (2001), 61-65.

[3] Oczoś K.E.: Kształtowanie ceramicznych materiałów technicznych, Oficyna Wydawnicza Politechniki Rzeszowskiej, Rzeszów 1996.

[4] Materiały informacyjne firmy CEREL, http://www.cerel.eu.

[5] Stryczek R., Pytlak B.: Elastyczne programowanie obrabiarek, Wydawnictwo Naukowe PWN, Warszawa 2011.

[6] http://support.automation.siemens.com.

[7] Porzycki J.: Modelowanie szlifowania osiowego zewnętrznych powierzchni walcowych, Oficyna Wydawnicza Politechniki Rzeszowskiej, Rzeszów 2004. 


\section{PARAMETRIC PROGRAMMING OF GRINDING OF CERAMIC PRODUCTS} WITH COMPLEX GEOMETRY

Abstract

Machining of technical ceramic products requires application of CNC machines which have predetermined technological possibilities, special grinding tools and properly made control programs. In this paper parametric programming of ceramic products machining using $\mathrm{CNC}$ grinding machine with $\mathrm{C}$ axis is described. Time analysis of machining of type dimension ceramic products with parametric geometry is also presented.

Keywords: parametric programming, grinding, CNC grinding machine, ceramic products

DOI: $10.7862 / \mathrm{rm} .2012 .8$ 